\title{
New Host-strains for the Lysogenic Corynebacterium diphtheriae PARK WILLIAMS No. 8 Strain
}

\author{
By PAULA MAXIMESCU \\ Department of Diphtheria and National Lysotyping and Bacteriophage \\ Centre, 'Dr I. Cantacuzino' Institute, Bucharest, Rumania
}

(Accepted for publication 22 March 1968)

\section{SUMMARY}

Investigation of the lysogenicity of seven Corynebacterium diphtheriae PW 8 variants revealed the spontaneous liberation, by these strains, of phage particles active against two $C$. ulcerans strains (9304 and $298 \mathrm{G}$ ) which are sensitive to $C$. diphtheriae gravis and mitis phages. By this means, phage particles with different host-range activity and morphology of plaques were obtained from the PW 8 strains. Further studies showed that some $C$. diphtheriae strains which possess the same sensitivity towards gravis and mitis phages showed the same spontaneous liberation of PW 8-carried phages. The newly obtained phages were able to convert to toxinogenesis both $C$. ulcerans and $C$. diphtheriae strains.

\section{INTRODUCTION}

During the course of lysotyping certain strains of Corynebacterium diphtheriae, received from Dr D. T. Simmons of the Commonwealth Serum Laboratories, Melbourne, Australia, we observed that some of the strains spontaneously liberated phage particles active against two $C$. ulcerans strains, 9304 and $298 \mathrm{G}$. The C. ulcerans strains were recently isolated in Rumania and were used as indicator strains for diphtheria phages. Since one of the lysogenic strains from Australia was labelled intermedius C.S.L. TORONTO (referred to as TORONTO), we assumed it to be the Toronto variant of the $C$. diphtheriae $\mathrm{PW} 8$ strain and consequently tested it for toxinogenicity in a static broth culture. The identity of the strain TORONTO was established by the production of diphtheria toxin of high potency (IOO Lf per $\mathrm{ml}$.) and demonstrating similar lysogenic capacity in all Pw 8 collection variants existing in the Diphtheria Department of the 'Dr I. Cantacuzino' Institute. The strain isolated by Park \& Williams ( 1896 ) and used for large-scale diphtheria toxin production in all countries is known to be different from most lysogenic toxinogenic $C$. diphtheriae strains since it carries a defective phage (Barksdale, Garmise \& Horibata, I960; Barksdale, Garmise \& Rivera, I96I ; Matsuda \& Barksdale, I966, I967). Since our observation was in disagreement with the findings of others which stated the defective inducible nature of the PW 8-carried phage, a detailed study was begun to demonstrate more conclusively the spontaneous liberation of phage particles by the PW 8 strains. At the same time, we tried to analyse the relationship existing between PW 8 and C. ulcerans strains and to find, if possible, other receptive strains to confirm the spontaneous liberation of PW 8 phages. 


\section{METHODS}

Corynebacteria strains. The following Corynebacterium diphtheriae $\mathrm{PW} 8$ variants from the collection of the Diphtheria Department of the 'Dr I. Cantacuzino' Institute: the WEISSENSEE and DESSAU strains, received from the Weissensee Institute at Berlin; CN 2000, received from the Rijks Instituut vor de Volksgezondheid at Utrecht; MASSACHUSETTS and CN 2000 from the Human Institute at Budapest (the cultures labelled CN 2000 came originally from the Wellcome Research Laboratories, Beckenham, Kent, England, CN 2000 being their number for their original PW 8 strain); and the 474 strain received from the Pasteur Institute, Paris; the Australian strain TORONTo from the Commonwealth Serum Laboratories, Melbourne; the C. ulcerans strains were isolated in Rumania, 9304 (-) tox - from a healthy human carrier, and $298 \mathrm{G} \mathrm{(-)}$ tox - from a horse.

Other strains used were Freeman's Corynebacterium diphtheriae mitis strains nos. 770, 4I I, 444, II74, II80; the $C$. diphtheriae mitis-like strains nos. A 003, A 028, C 43, S 038 supplied by Dr N. B. Groman of the Department of Microbiology, University of Washington, Seattle; and the C. belfanti ro3o strain received from Dr H. Oehring of the Hygiene Institut, Friedrich Schiller Universität, Jena. The 9304 (W) tox + strain was derived from the 9304 (-) tox - strain lysogenized with PW 8 phage.

All strains were investigated for their morphology, biochemical behaviour and in vitro toxin production according to the minimal requirements of the scheme for bacteriological diagnosis of Corynebacterium diphtheriae (Bulletin, 1965).

Detection of lysogeny. The method used for demonstrating liberation of phages was previously described by Saragea \& Maximescu (1964). This method demonstrates phage particles, spontaneously liberated from the lysogenic strain in shake culture, by the spot method on agar plates of the sensitive indicator strain.

Toxinogenicity. Tests were performed on filtrates of Pope-Linggood broth cultures of the lysogenized strains: (I) in rabbit skin by the method of Fraser (I93I); (2) by the subcutaneous inoculation of guinea-pigs; and (3) by in vitro inoculation of monkey kidney tissue cultures. Quantitative determination of large amounts of diphtheria toxin was done by the flocculation test of Ramon \& Richou (1950).

The phage types of all strains were established according to the lysotyping scheme for Corynebacterium diphtheriae (Saragea \& Maximescu, 1964, 1966).

\section{RESULTS}

\section{Lysogenicity of $P W 8$ variants}

The lysogenicity testing of the PW 8 variants (WEISSENSEE, DESSAU, CN 2000 from Utrecht, MASSACHUSETTS and CN 2000 from Budapest, 474, and TORONTO), carried out with stock cultures of each strain, showed spotaneous liberation of phages of Corynebacterium ulcerans strains 9304 (-) tox - and 298 G (-) tox -. Previous tests performed with $C$. ulcerans strains had established that they were non-lysogenic and nondiphtheria toxin producers. Appearances of lysis with punctiform plaques were noted. By multiplication of the WEISSENSEE, CN 2000 Utrecht, and TORONTO lysates on the $9304(-)$ tox - C. ulcerans strain, the three phage preparations, 'W', ' $U$ ', ' $T$ ', with confluent lysis were obtained. The new phage preparations lysed mainly the C. ulcerans strains, but had also a weaker activity (a few plaques) on Freeman's strain C. diphtheriae 770 (Table I). 
Considering that all PW 8 variants used in this study were stock cultures and that in general among populations of the high toxinogenic PW 8 strain mutants occur displaying different lysogenic qualities (Barksdale et al. 196I), we tried to repeat the lysogenicity test, starting from isolated colonies of the WEISSENSEE and CN 2000 variants. The tests performed show similar results (Table 2).

Table I. Activity of phage particles spontaneously released by WEISSENSEE, CN 2000 and TORONTO strains

\begin{tabular}{|c|c|c|c|c|c|c|}
\hline \multirow[b]{2}{*}{$\begin{array}{c}\text { Sensitive } \\
\text { strains }\end{array}$} & \multicolumn{2}{|c|}{ PW 8, WEISSENSEE } & \multicolumn{2}{|c|}{ PW 8, CN 2000 Utrecht } & \multicolumn{2}{|c|}{ TORONTO } \\
\hline & $\begin{array}{l}\text { Original } \\
\text { lysate* }\end{array}$ & Phage 'W' $\dagger$ & $\begin{array}{l}\text { Original } \\
\text { lysate* }\end{array}$ & Phage 'U' $\dagger$ & $\begin{array}{l}\text { Original } \\
\text { lysate* }\end{array}$ & Phage ' $T$ ' $\dagger$ \\
\hline 9304 & $\begin{array}{l}\text { Scanty punctiform } \\
\text { plaques }\end{array}$ & $\mathrm{OL}$ & $1+s$ & $\mathrm{OL}$ & $1+s$ & OL \\
\hline $298 \mathrm{G}$ & $\begin{array}{l}\text { Scanty punctiform } \\
\text { plaques }\end{array}$ & $\mathrm{OL}$ & $1+s$ & $\mathrm{OL}$ & $1+s$ & $\mathrm{OL}$ \\
\hline 770 & - & $\begin{array}{l}\text { Isolated, } \\
\text { normal-sized } \\
\text { plaques }\end{array}$ & . & $\begin{array}{l}\text { Isolated, } \\
\text { normal-sized } \\
\text { plaques }\end{array}$ & . & $\begin{array}{l}\text { Isolated, } \\
\text { normal-sized } \\
\text { plaques }\end{array}$ \\
\hline
\end{tabular}

* An overnight shake culture of the stock Pw 8 strains. $1+\mathrm{s}=>50$ small, punctiform plaques.

$\dagger$ Phages ' $W$ ', ' $U$ ' and ' $T$ ' originated from the multiplication of the spontaneously released PW 8 phage particles on the $9304(-)$ tox - C. ulcerans strain. $\mathrm{OL}=$ opaque lysis.

Table 2. The lysogenic state of some isolated colonies from the highly toxinogenic WEISSENSEE and CN 2000 strains

$\begin{array}{cccc}\text { Colony } & \begin{array}{c}\text { Diphtheria } \\ \text { toxin, pro- } \\ \text { duced in } \\ \text { static } \\ \text { culture }\end{array} & \begin{array}{c}\text { Type of lysis obtained on } \\ \text { C. ulcerans } \text { strains } 9304 \\ \text { and } 298 \mathrm{G}\end{array} \\ \text { no. } & \text { (Lf/ml.) } & \text { Scanty punctiform plaques } \\ \text { PW 8, } & \text { II } & \text { I00 } & \text { Scanty punctiform plaques } \\ \text { WEISSENSEE } & \text { II3 } & 90 & \text { Scanty punctiform plaques } \\ \text { II } & \text { II5 } & 70 & 1+\mathrm{s}^{*} \\ \text { PW 8, CN 2000 } & \text { II6 } & 95 & 1+\mathrm{s}^{*} \\ & \text { II7 } & 95 & 1+\mathrm{s}^{*}\end{array}$

Starting from isolated plaques of the ' $\mathrm{W}$ ' phage on plates with different host strains (9304, 770 and 4I I), three kinds of phage preparations with different spectra of activity were obtained (Table 3 ).

The similarity of the host-range activity of the W/4II and Freeman's B phage is remarkable. Attention is also drawn to (I) the minute plaques of the W/9304 phage obtained on Corynebacterium ulcerans strains (Pl. I, fig. I $a, b)$; (2) the normal size plaques of the W/770 and W/4 I I phages; and (3) the different behaviour towards PW 8 phages of the 770 strain among Freeman's other strains (Table 3). 
Table 3. Host range of $P W 8$ phages as compared with Freeman's $B$ phage

\begin{tabular}{ccccc} 
Indicator & \multicolumn{4}{c}{ Bacteriophage } \\
\cline { 2 - 5 } strains & $\mathrm{W} / 9304^{*}$ & $\mathrm{~W} / 770^{*}$ & $\mathrm{~W} / 4^{1 I^{*}}$ & Freeman's phage B \\
$41 \mathrm{II}$ & $\cdot$ & $\cdot$ & $\mathrm{CL}$ & $\mathrm{CL}$ \\
444 & $\cdot$ & $\cdot$ & $\mathrm{CL}$ & $\mathrm{CL}$ \\
$\mathrm{II74}$ & $\cdot$ & $\cdot$ & $\mathrm{CL}$ & $\mathrm{CL}$ \\
1180 & $1+\mathrm{n}$ & $\mathrm{OL}$ & $\mathrm{CL}$ & $\mathrm{CL}$ \\
770 & $\mathrm{CL}$ & $\mathrm{CL}$ \\
9304 & $\mathrm{OL}$ & $1+\mathrm{n}$ & $1+\mathrm{n}$ & $1+\mathrm{n}$ \\
$298 \mathrm{G}$ & $\mathrm{OL}$ & $1+\mathrm{n}$ & $1+\mathrm{n}$ & $1+\mathrm{n}$
\end{tabular}

* Each of the PW 8 phages was obtained by multiplication of a single titre plaque from the original lysate of the WEISSENSEE strain seeded on the growth of the 9304, 770 and 4 I I strains.

$\mathrm{CL}$, Clear confluent lysis; OL, opaque confluent lysis; $1+n,>50$ normal-sized plaques.

\section{Lysogenic conversion by $\mathrm{PW} 8$ phages}

The lysogenization by PW 8 phages of the $9304(-)$ tox - Corynebacterium ulcerans and $770(-)$ tox $-C$. diphtheriae mitis strains demonstrates their converting capacity. Single colonies isolated from the lysis area on solid medium (for each phage, 20 colonies from the respective strain) were tested in parallel with an equal number of colonies from the original strain. The results showed different rates of conversion (20/20) for the C. diphtheriae $770(-)$ tox - and (5/20) C. ulcerans $9304(-)$ tox strains. The conversion of the C. ulcerans $9304(-)$ tox - strain caused us to analyse the change produced in the lysogenized population in greater detail. For demonstration of the newly formed diphtheria toxin by the lysogenized C. ulcerans (9304 (W) tox + ) cultures, the in vitro Elek precipitation test, the in vivo test on rabbit skin (P1. I, fig. $2 a, b$ ), the in vivo guinea-pig inoculation test and in vitro tissue culture inoculation (P1. 2 fig. $3 a, b$ ) were set up. The results, which are presented in Table 4, show the identity of the newly produced toxin with diphtheria toxin.

The lysogenized diphtheria-toxinogenic 9304 (W) tox + strain did not change the morphological, biochemical and biological behaviour of a $C$. ulcerans strain, but became resistant to lysis by PW 8 phages.

The phage liberated by the 9304 (W) tox + strain had the same capacity to convert the original $9304(-)$ tox - strain to toxinogenicity as the original phages released by PW 8 strains.

\section{Other strains receptive for the spontaneously released $\mathrm{PW} \&$ phage particles}

In view of the fact that Corynebacterium ulcerans and $C$. diphtheriae strains are closely related (Petrie \& McClean, I934; Jebb, I948; Jebb \& Martin, I965), we considered that the receptivity of the two C. ulcerans strains for PW 8 phages is not due to their specificity as $C$. ulcerans strains, but to their wide receptivity for diphtheria gravis and mitis phages. For this reason, we selected from the Diphtheria Department's collection some strains which presented this feature (Table 5): C. diphtheriae mitis-like strains nos. A 003, A 028, C 43, s 038, and C. belfanti strain no. 1030. All these strains were receptive for spontaneously released PW 8 phages (Pl. 2, fig. 4). 


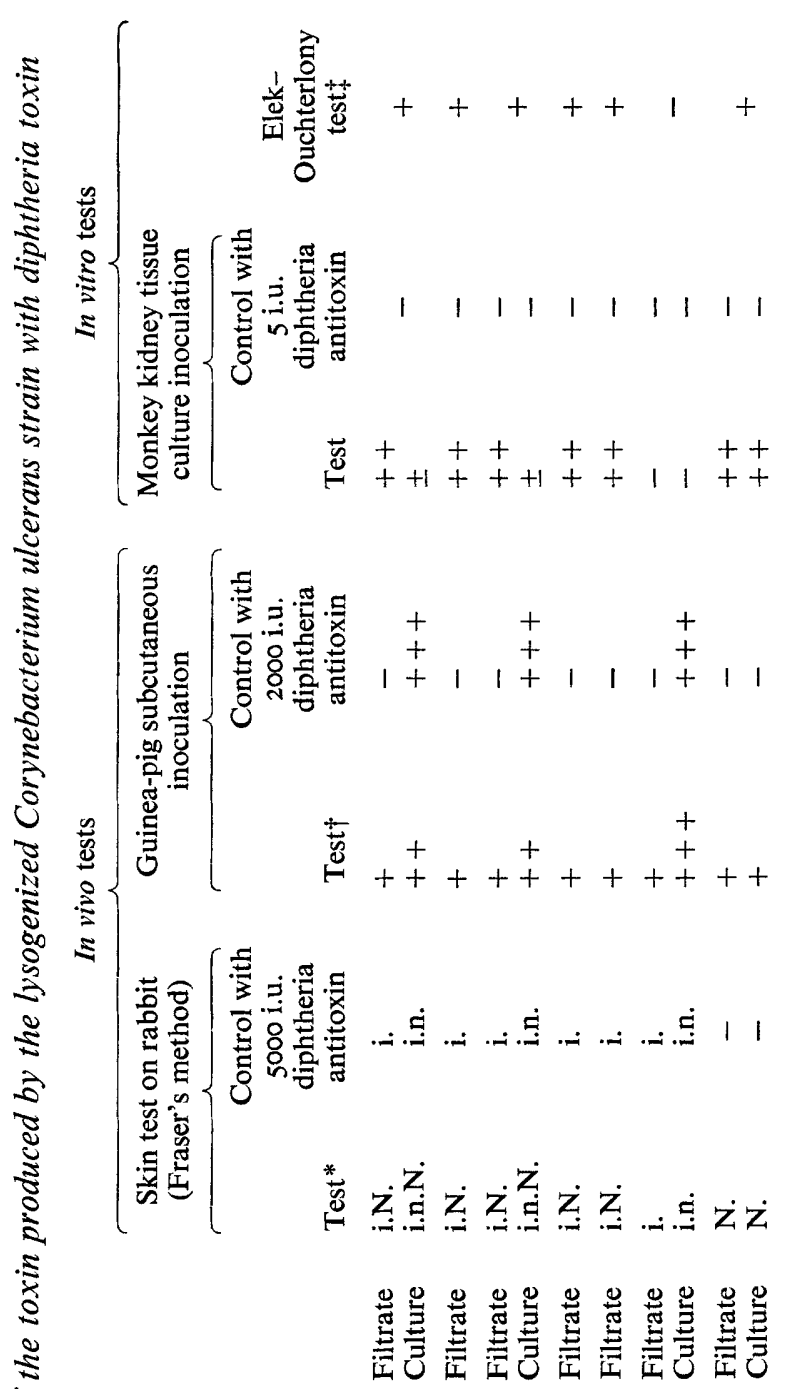

ఫु

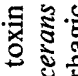

蛋

号 昰记

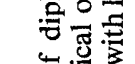

II

$\ddot{3}$

鱼. 表

융

气 हี่

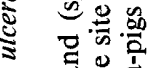

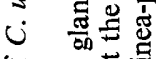

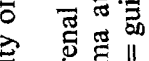

递焉 +

焉

总

品 $\frac{8}{0.09}$

흘

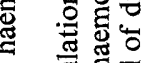

II

$\because \approx 3$ 突

농응

电家

ป ता

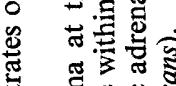

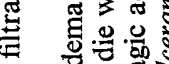

。

\&

월

离

:

$\stackrel{2}{\Sigma}$

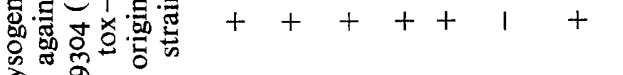

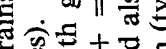

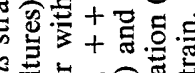

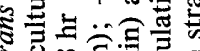

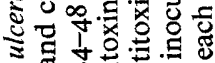

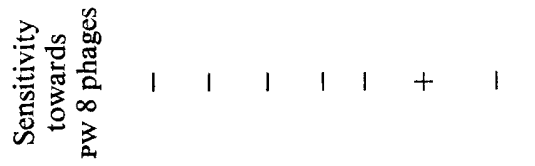

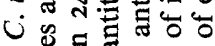

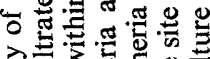

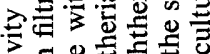

용

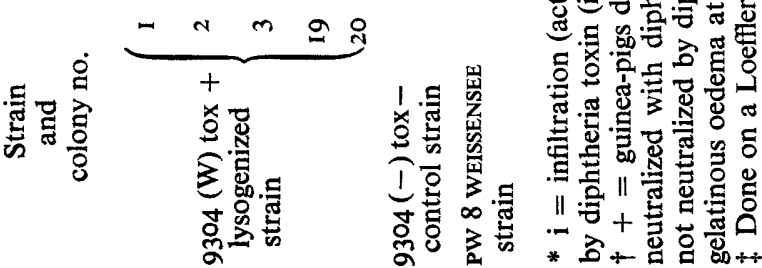

G. Microb. 53 
象蜜

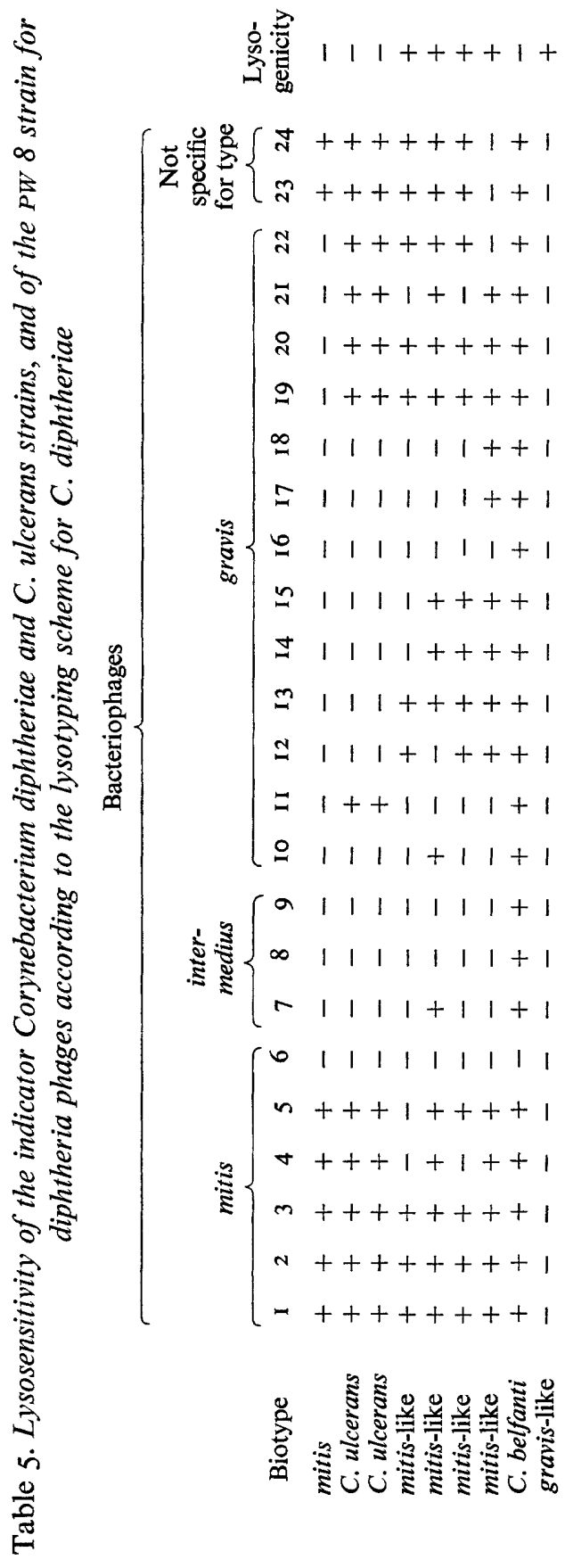

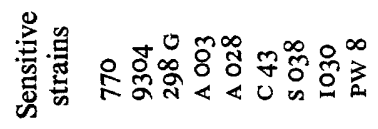




\section{DISCUSSION}

The synthesis of diphtheria toxin occurs through a mechanism controlled by the gene of a bacteriophage which converts the receptive host to lysogeny and at the same time confers upon it the tox + character (Freeman, 195I ; Barksdale, 1959). In general, toxinogenesis and lysogenicity are correlated and the presence of the tox + character implies carriage of a bacteriophage, the detection of which is dependent on the availability of a host strain. This fact became obvious to us on numerous occasions when apparently non-lysogenic, toxinogenic Corynebacterium diphtheriae strains liberated a bacteriophage which could be detected only when tested on a larger set of sensitive strains. By this means the prophage is not difficult to demonstrate. Numerous studies on the mechanism of diphtheria toxin production have focused attention on the behaviour of the highly toxinogenic PW 8 strain. Such studies demonstrated that this strain differs from most lysogenic $C$. diphtheriae strains by the defective phage it carries, which harbours a genetic block that prevents the formation of mature phage (Barksdale, 1959); for this reason, although generally phage liberation and toxin synthesis are closely correlated, this correlation could not be established with the PW 8 strain (Matsuda \& Barksdale, I966). In the present work, using two $C$. ulcerans and some $C$. diphtheriae strains which present the same wide receptivity to diphtheria gravis and mitis phages, we were able to demonstrate the spontaneous liberation of phage particles by PW 8 strains, with different host range activity, amongst which one was similar to Freeman's phage B. Thus our findings agree with those of Miller, Pappenheimer \& Doolittle (1966), who demonstrated in the PW 8 lysate a blocking antigen for anti-B phage sera which caused them to state: 'It is at least as likely that the PW 8 strain carries a normal phage genome...', and with those of Mathews, Miller \& Pappenheimer (1966), who showed by electron-microscope photographs a phage resembling phage B in PW 8 lysates. In the present investigation, using suitable host strains, the presence of prophage was easily demonstrated.

Thus the results of this investigation open some new aspects of the PW 8 strain: PW 8 strains are not defective lysogenically, but spontaneously liberate phage particles with different host-range activity; the host strains which display spontaneous liberation of PW 8 phages (Corynebacterium ulcerans, C. diphtheriae mitis-like, and C. belfanti) are strains sensitive for a large number of diphtheria gravis and mitis phages; phages released by PW 8 strains convert to diphtheria toxinogenesis sensitive strains of both C. ulcerans and $C$. diphtheriae; all PW 8 variants are resistant to a large number of gravis, intermedius and mitis phages.

The possibility of demonstrating by means of the new host strains the spontaneous release of PW 8-carried phages, and the classification of the PW 8 strain, according to our conception, as an atypical gravis type (McLeod, 1943) opens new prospects for the study of phage-host relationships and bacteriophage-directed synthesis of diphtheria toxin-as well as for the 'iron effect' (Matsuda \& Barksdale, 1967) in this highly toxinogenic strain.

I wish to express my gratitude for their helpful criticism to Professors Drs M. Ciucă and N. Nestorescu, Heads of the National Centre for Lysotyping and Bacteriophage References in the 'Dr I. Cantacuzino' Institute, and to Professor Dr I. Mesrobeanu, Director of the 'Dr I. Cantacuzino' Institute, for the excellent conditions given for 
this work. I also wish to thank Dr D. T. Simmons of the Commonwealth Serum Laboratories, Melbourne, Australia, Dr N. B. Groman of the Department of Microbiology, the University of Washington, Seattle, and Dr H. Oering of the Hygiene Institut of the Friedrich Schiller Universität, Jena, for kindly sending us strains from their collections. I should like to thank Dr Alice Saragea for encouragement, valuable advice and discussions throughout this study. I am indebted to V. Gane for the photographs.

\section{REFERENCES}

BARKSDALE, L. (I959). Lysogenic conversion in bacteria. Bact. Rev. 23, 202.

BarksDale, L., Garmise, L. \& Horibata, K. (1960). Virulence, toxinogeny and lysogeny in Corynebacterium diphtheriae. Ann. N.Y. Acad. Sci. 88, 1093.

Barksdale, L., Garmise, L. \& Rivera, R. (1961). Toxinogeny in Corynebacterium diphtheriae. J. Bact. $81,527$.

Bulletin of the Ministry of Health \& Welfare (1965). Diagnosticul de laborator al difteriei, no. 6, 30.

FrASER, D. T. (I93I). The technique of a method for the quantitative determination of diphtheria antitoxin in rabbits. Trans. $R$. Soc. Can. V, $25,175$.

Freeman, V. J. (195I). Studies on virulence of bacteriophage infected strains of Corynebacterium diphtheriae. J. Bact. 6r, 675.

JebB, W. H. H. (1948). Starch-fermenting, gelatin-liquefying Corynebacteria isolated from the human nose and throat. J. Path. Bact. 6o, 403.

JeBb, W. H. H. \& MARTIN, T. D. M. (1965). A non starch-fermenting variant of Corynebacterium ulcerans. J. clin. Path. r8, 757.

Mathews, M. M., Miller, P. A. \& Pappenheimer, A. M., Jun. (1966). Morphological observations on some diphtherial phages. Virology 29, 402.

Matsuda, M. \& BarksDale, L. (1966). Phage-directed synthesis of diphtherial toxin in nontoxinogenic Corynebacterium diphtheriae. Nature, Lond. 210 , $91 \mathrm{I}$.

Matsuda, M. \& BarksDale, L. (1967). System for the investigation of the bacteriophage-directed synthesis of diphtherial toxin. J. Bact. 93, 722.

MCLeOD, J. W. (1943). The types mitis, intermedius and gravis of Corynebacterium diphtheriae. A review of observations during the past ten years. Bact. Rev. 7, I.

Miller, P. A., Pappenheimer, A. M., Jun. \& Doolitrle, W. F. (1966). Phage-host relationship in certain strains of Corynebacterium diphtheriae. Virology 29, 410.

Park, H. W. \& Williams, A. W. (1896). The production of diphtheria toxin. J. exp. Med. I, I64.

Petrie, G. F. \& MCLean, D. (1934). The inter-relations of Corynebacterium ovis, Corynebacterium diphtheriae, and certain diphtheroid strains derived from the human nasopharynx. J. Path. Bact. 39, 635 .

Ramon, G. \& Richou, R. (1950). Sur le titrage des anatoxines diphthérique, staphylococcique et tétanique. Revue Immunol. Thér. antimicrob. 4I, I50.

Saragea, A. \& Maximescu, P. (1964). Schema provisoire de lysotypie pour Corynebacterium diphtheriae. Archs roum. Path. exp. Microbiol. 23, 817.

Saragea, A. \& Maximescu, P. (1966). Phage-typing of Corynebacterium diphtheriae. Incidence of C. diphtheriae phage-types in different countries. Bull. Wld Hlth Org. 35, 685.

\section{EXPLANATION OF PLATES}

\section{Plate I}

Fig. I. Plaques produced by Pw 8 phages on Corynebacterium strains. $a$, Minute plaques produced on $9304(-)$ tox - Corynebacterium ulcerans strain. $b$, Normal size plaques produced on $C$. diphtheriae strains. Magnification of both $a$ and $b \times 20$.

Fig. 2. Skin tests in rabbits of toxic filtrates with and without diphtheria antitoxin. $a: 1$, Corynebacterium ulcerans filtrate from 9304 ( - ) tox $-; 2$ and 3, filtrate from 9304 (W) tox + lysogenized strain; 4 , PW 8 diphtheria toxin. $b$, The filtrates, in the same order, with diphtheria antitoxin. It will be seen that the PW 8 toxin is neutralized in 4, and also the necrosis in 2 and 3. 

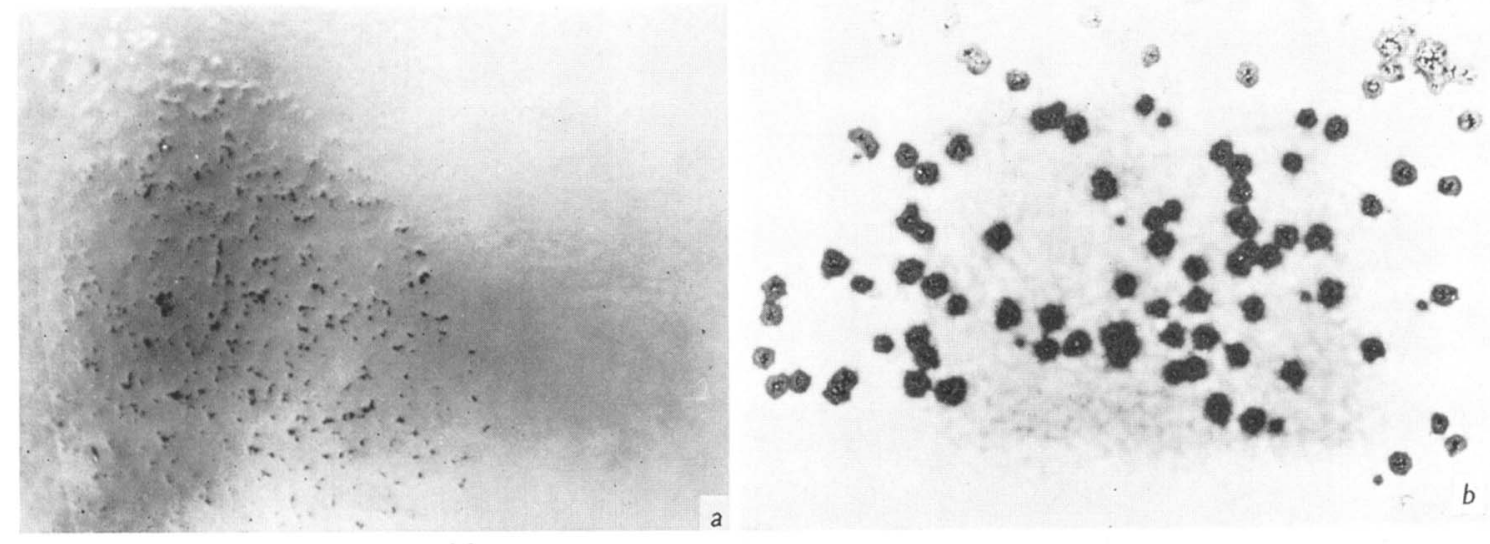

Fig. 1
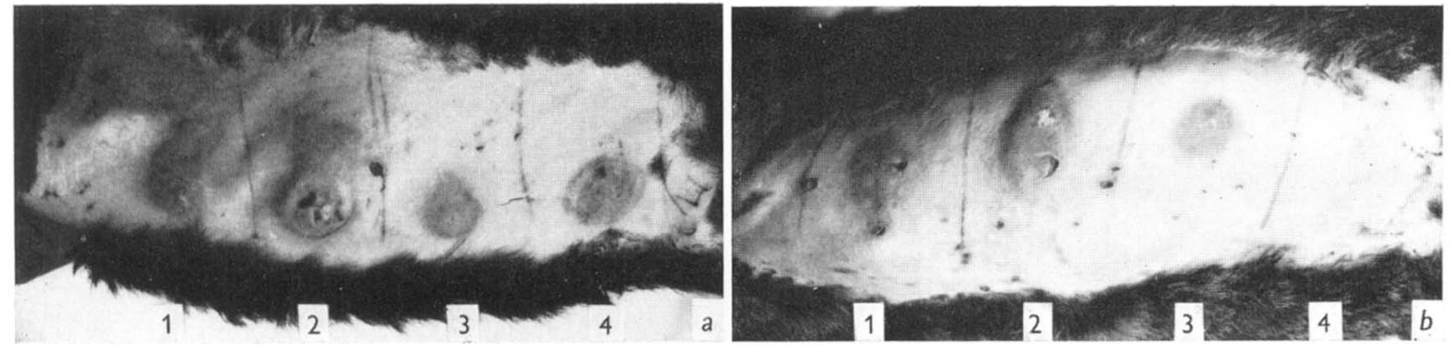

Fig. 2 
Journal of General Microbiology, Vol. 53, No. I

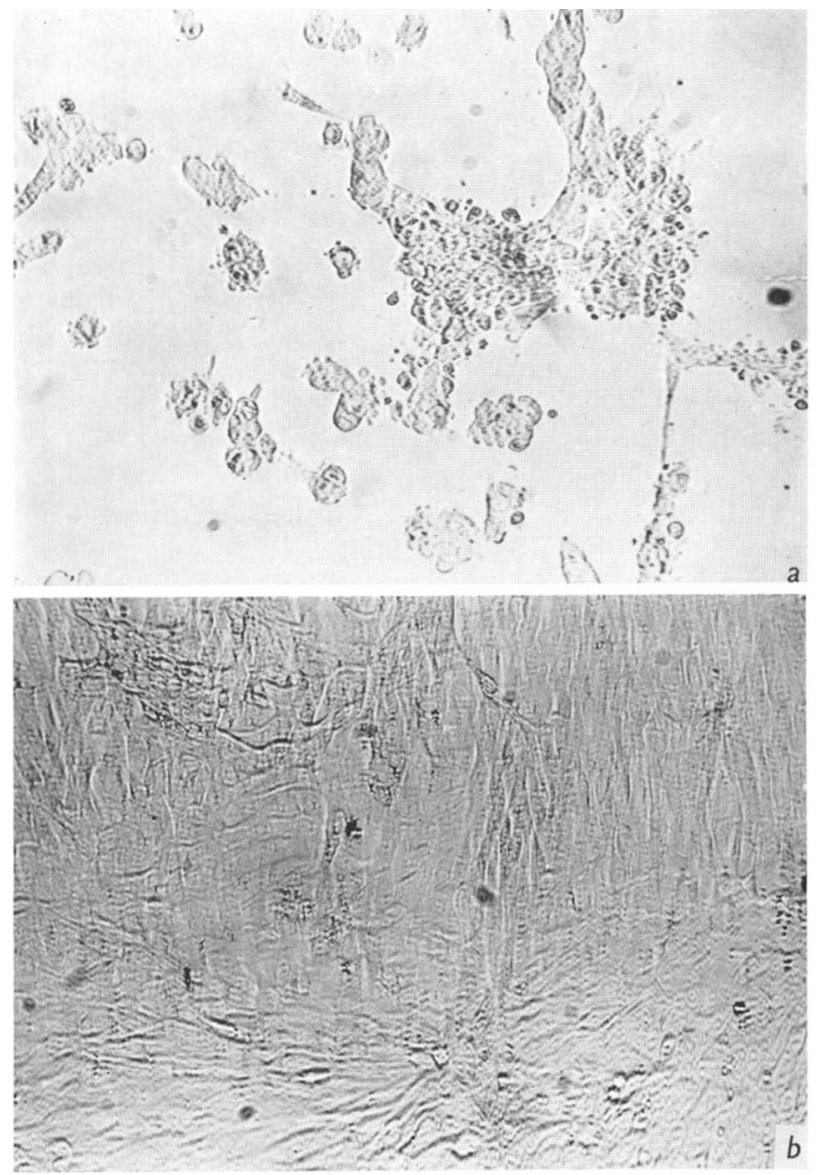

Fig. 3

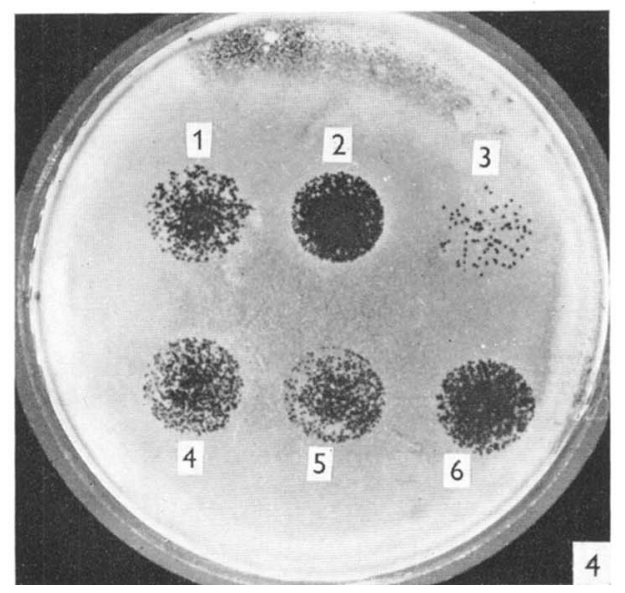

P. MAXIMESCU 
Plate 2

Fig. 3. Cytopathogenic effect of filtrate on monkey tissue. $a$, Cytopathogenic effect of 9304 (W) tox + filtrate on monkey tissue culture. $b$, Similar tissue culture in which toxic effect of $9304(\mathrm{~W})$ tox + filtrate has been neutralized with diphtheria antitoxin.

Fig. 4. Lysis produced by spontaneously released PW 8 phages by (I) WEISSENSEE, (2) CN 2000 Budapest, (3) MASSACHUSETTS, (4) WEISSENSEE, (5) CN 2000 Utrecht, (6) TORONTO strains seeded on a growth of Corynebacterium belfanti strain 1030 . 